\title{
Ruben Michael Ceballos: Bioethanol and Natural Resources; Substrates, Chemistry and Engineered Systems
}

\author{
Ken Jones ${ }^{1}$ \\ ๑) Springer-Verlag GmbH Germany, part of Springer Nature 2018
}

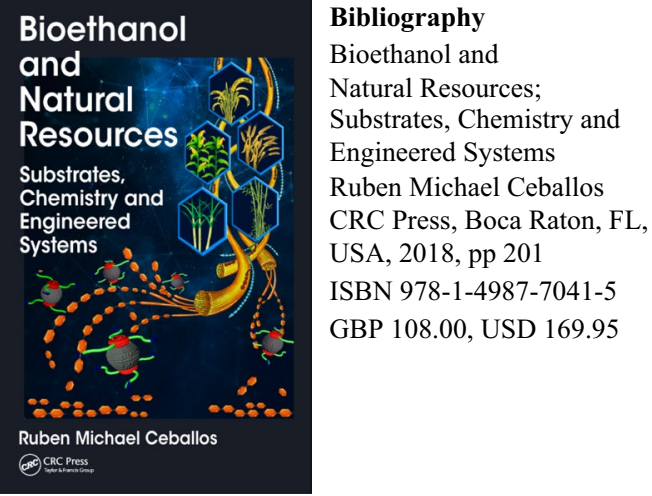

Adoption of alternative energy sources, and more specifically liquid automotive fuels, is hugely influenced by two factors: environmental considerations, and the price of conventional crude oil. The latter has fluctuated enormously, ranging in the last decade alone from \$35 to \$147/ bbl. Global crude demand is forecast to grow over the next decade, despite the expected replacement of the IC engine by electrically driven vehicles (EVs) - but this factor will not drive crude prices much above their current price of around $\$ 66 / \mathrm{bbl}$; Fracked oil, in essence the volatile more valuable end of conventional crude, is now the 'swing' producer, based on the fact the State of Texas alone contains far more recoverable 'condensate' reserves than even the Saudi's giant Ghawar Field.

What then is bioethanol going to compete on? Sustainability is stressed throughout the book, implying that crude oil is a finite resource, and depleting. A true statement, but time scales need to be included to support this assertion. Most commentators ignore the impact of EVs, as is the case here. "Thus, the days of fossil-based liquid fuel that dominated the market may be numbered, and the era of diverse, reasonably priced (the only mention of cost in the book), and readily accessible alternative biofuels, may be on the horizon"; and "the demand for liquid (or gas) fuel alternatives will exceed what is capable of being supplied by fossil-based fuel resources". These statements are so far away from reality as to be risible.

The technical matter is covered in four chapters, and is little more than a summary of the technologies that can be used to break down the cellulosic, starch, sucrose, corn, bagasse, straw and other feedstocks that have been used to create alternative fuel bases, followed by 85 pages of cited references (some $40 \%$ of the total number of pages). In summary this book has all the appearance of a literature survey that has to precede a $\mathrm{PhD}$ thesis-before the practical work begins.

Ken Jones

chromatographia@springer.com

1 Knutsford, UK 